\title{
Monitoring of Temperature Distribution and Vegetation Index on Volcanic Hazard Eruption with Landsat-8 Thermal Infrared Sensor Imagery
}

\author{
Hendro Murtianto \\ Department of Geography Education \\ Indonesia University of Education \\ Bandung, Indonesia \\ Corresponding email: thiyan_cakep@yahoo.com \\ Jupri \\ Department of Geography Education \\ Indonesia University of Education \\ Bandung, Indonesia \\ Yakub Malik \\ Department of Geography Education \\ Indonesia University of Education \\ Bandung, Indonesia
}

\begin{abstract}
National Aeronautics and Space Administration (NASA) launched the new satellite mission called Landsat-8 on February 11, 2013. NASA improved Landsat-8 with Onboard Operational Land Imager (OLI) and Thermal Infrared Sensor (TIRS) sensors separated to 11 spectral bands. Volcanic eruption spreads a lot of materials from magma chamber. High temperature of lava flow, pyroclastic flow, steam gas and ash-fall carried specific signal that can be detected easily by TIRS band 10 and 11 of Landsat-8. Mount Kelud on Java Island, Indonesia erupted on February 14, 2014 and deployed ash up to 5 centimeters thick on land forcing airports and major tourist destinations closed. It distributed millions ton of ash-fall within an eruption. Volcanic ash fall contain tiny crystalline silica, minerals quartz, cristobalite, and tridymite that can disturb to ecosystem. Ash-fall can have detrimental effects on vegetation depending on ash thickness accumulation, ash-fall intensity, contained minerals and vegetation growing characteristics. Atmosphere condition shift rapidly with temperature distinction which is caused of volcanic ash eruption. Rapidly temperature change can effect to leaf and plant condition. Generally, healthy leaves absorb most of the visible light that falls on it, and reflects a large portion of the near-infrared light. Otherwise, unhealthy leaves reflect more visible light and less near-infrared light. In this study, the differences reflectance that were caught by Landsat-8 sensor describe the relationship between volcanic eruption, temporary temperature change and vegetation response. This observation handled from November (before eruption) to March 2014 (after eruption). Study purposes are to know temperature distribution and vegetation index impact from volcanic hazard eruption. Sets satellite images from United States Geological Survey (USGS) were used to know vegetation reflectance differences. The results of this study are volcanic ash-fall related to changing of temperature, comparing NDVI that showed exsiccate vegetation and growing leaves speed at post volcanic eruption.
\end{abstract} fall

Keywords-Landsat-8, thermal remote sensing, volcanic ash-

\section{INTRODUCTION}

Transferring magma and gas from beneath the Earth's crust to a position above is a process in volcanic eruption. Volcanic eruption spreads a lot of materials from magma chamber. It will modify the Earth's surface and its atmosphere conditions in a variety effect in range of spatial and temporal scales. The effect of an eruption depends on the characteristics of the volcano, type of eruption, the period of time over, geochemistry of materials and scope of the area distribution materials of eruption (Robert Wright et.al: 2015). Volcanic eruption can change the geomorphological, hydrological, and ecological characteristics of the landscape surrounding the volcano, while the adding materials and gasses into Earth's surface and atmosphere not only modifies its composition and thickness but also it can impact to regional weather and global climate.

The remote sensing study for observing volcanic eruption had reached and developed to the infrared sensors of remote sensing. Various research and observations from both aerial and spaceborne platforms, utilizing some of the most up to date and sensitive sensors to detect and monitor global volcanic activity (Ramsey at.al: 2012). Active volcanic surfaces are particularly amenable to their remote study using thermal infrared detectors by virtue of their emission of heat. Indeed, the thermal emissions of an active volcanic surface relate directly to the volcanic activity at a specific time, be it a fresh lava flow, active lava lake or a subtly warm fumarole field. A significant benefit of such studies is the potential to 
gather data while avoiding the risks and costs associated with on-the-ground volcanic fieldwork (Matthew Blackett: 2014). Landsat 8 sensors, such as the previous satellite launched, have aims to get good and validate remote sensing data for observing and monitoring earth surface and atmosphere. With its thermal sensors, Landsat 8 data has capability to record volcanic activity and eruption disaster.

Mount Kelud located on East Java Province, Indonesia, erupted on February 14, 2014 and deployed ash up to 5 centimeters thick on land forcing airports and major tourist destinations closed. Mount Kelud eruption is very special, It can spare millions ton of ash fall within an eruption. Volcanic ash fall contain tiny crystalline silica, minerals quartz, cristobalite, and tridymite that can disturb to ecosystem. Ash fall can have detrimental effects on vegetation depending on ash thickness accumulation, ash fall intensity, contained minerals and vegetation growing characteristics. Impacts from volcanic ash fall on the environment have consequences of turning ecosystem condition, such as vegetation. Assessing volcanic ash fall impact on vegetation can be analyzed using remote sensing data and utilities. Various study of remote sensing that aim to know vegetation characteristics appeared great results evidence. Comparing bands of satellite images become index is common technique used to know leaves and trees conditions. This article focus on identifying temperature distribution change affected by volcanic eruption and analyzing differences of NDVI on both of time, before and after eruption.

\section{A. Landsat 8 and volcanic monitoring}

Landsat- 8 was developed by National Aeronautics and Space Administration (NASA) and the United States of Geological Survey (USGS). NASA launched Landsat-8 satellite on February 11, 2013. Earth Resources Observation and Science (EROS) center manages of all data post-launch calibration activities, satellite operations, data product generation and archiving. The Landsat 8 satellite consists of two science instruments: the Operational Land Imager (OLI) and the Thermal Infrared Sensor (TIRS). These two sensors provide seasonal coverage of the global landmass at a spatial resolution of 30 meters (visible, NIR, SWIR); 100 meters (thermal); and 15 meters (panchromatic).

TABLE 1. CHARACTERISTICS OF THE LANDSAT 8 OPERATIONAL LAND IMAGER (OLI) AND THERMAL INFRARED SENSOR (TIRS) BANDS

\begin{tabular}{|c|c|c|c|}
\hline Instruments & Bands & $\begin{array}{c}\text { Wavelength } \\
\text { (micrometers) }\end{array}$ & $\begin{array}{c}\text { Resolution } \\
\text { (meters) }\end{array}$ \\
\hline \multirow{4}{*}{ OLI } & $\begin{array}{c}\text { Band 1 - Coastal } \\
\text { aerosol }\end{array}$ & $0.43-0.45$ & 30 \\
\cline { 2 - 4 } & Band 2- Blue & $0.45-0.51$ & 30 \\
\cline { 2 - 4 } & Band 3 - Green & $0.53-0.59$ & 30 \\
\cline { 2 - 4 } & Band 4- Red & $0.64-0.67$ & 30 \\
\hline Instruments & Bands & $\begin{array}{c}\text { Wavelength } \\
\text { (micrometers) }\end{array}$ & $\begin{array}{c}\text { Resolution } \\
\text { (meters) }\end{array}$ \\
\hline \multirow{4}{*}{ OLI } & $\begin{array}{c}\text { Band 5 - Near } \\
\text { Infrared (NIR) }\end{array}$ & $0.85-0.88$ & 30 \\
\cline { 2 - 4 } & Band 6- SWIR 1 & $1.57-1.65$ & 30 \\
\cline { 2 - 4 } & Band 7 - SWIR 2 & $2.11-2.29$ & 30 \\
\cline { 2 - 4 } & $\begin{array}{c}\text { Band 8 - } \\
\text { Panchromatic }\end{array}$ & $0.50-0.68$ & 15 \\
\hline
\end{tabular}

\begin{tabular}{|c|c|c|c|}
\hline Instruments & Bands & $\begin{array}{c}\text { Wavelength } \\
\text { (micrometers) }\end{array}$ & $\begin{array}{c}\text { Resolution } \\
\text { (meters) }\end{array}$ \\
\hline & Band 9 - Cirrus & $1.36-1.38$ & 30 \\
\hline \multirow{3}{*}{ TIRS } & $\begin{array}{c}\text { Band 10 - Thermal } \\
\text { Infrared (TIRS) 1 }\end{array}$ & $10.60-11.19$ & 100 \\
\cline { 2 - 4 } & $\begin{array}{c}\text { Band 11 - Thermal } \\
\text { Infrared (TIRS) 2 }\end{array}$ & $11.50-12.51$ & 100 \\
\hline
\end{tabular}

The TIRS can detect temperature from Earth's surface in two separate bands, It provides more accurate data for atmospheric corrections than the previous satellite image of Thematic Mapper and Enhanced Thematic Mapper + that only used one thermal infrared band (Reuter D, et. al: 2010). Satellite sensors for monitoring disaster and hazard shows a great progress development, in this case used the thermal infrared bands for monitoring of volcanic eruption. Volcanic monitoring with satellite sensor divided to two major purposes of observation: atmospheric and ground observation. Monitoring eruption, ash clouds (Pieri D et. al: 2004) are examples for atmospheric observation for deciding safety flight and impact volcanic eruption coverage. On other side, ground monitoring has a great identification for mitigation just like the orientation of lava flow and its destruction. On new technology of Landsat 8, TIRS provides a better performance for measuring temperatures than the previous satellite images to monitor volcanic hazard eruption.

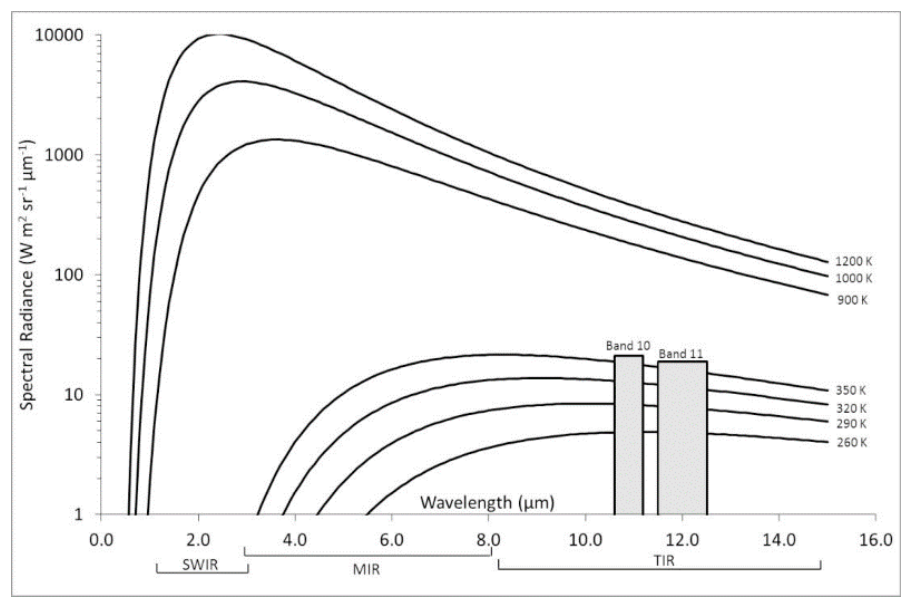

Fig. 1. The spectral range of sensitivity within which the TIRS bands (Landsat8 bands 10 and 11) operate, overlain on the Planck Function displaying the temperature range these bands are capable of detecting and, for comparison, the infrared emissions from surfaces at a range of temperatures (USGS: 2013).

\section{B. Normalized difference vegetation index (NDVI) and Volcanic Eruption}

The normalized difference vegetation index (NDVI) is a description that indicates the live green of crops, trees, leaves or land covers observed by remote sensing techniques and measurements. The monitoring of vegetation by remote sensing is an accepted technique of resource assessment (Tim Hess, et.al: 1996). Various remote sensing techniques have revealed compelling spectral relationships between the red and near-infrared (NIR) part of the spectrum to green vegetation. Remote sensing can provide an indirect measure of vegetation growth through the calculation of vegetation indices. The 
Normalized Difference Vegetation Index (NDVI) is one of the most generally used indices for vegetation monitoring. The NVDI is calculated as the normalized ratio between channel 1 (red) and channel 2 (near-infrared) data sensed by bands of Landsat-8 (Molly E. Brown, et.al: 2006).

Deriving vegetation indices from satellite image is often used as a monitoring tool for the vegetation health and dynamics, enabling easy temporal and spatial comparisons (Molly E. Brown, et.al: 2006). Detection of the ash impact on vegetation was performed using temporal analysis of the NDVI time series. Temporal change detection compares two periods in time by removing all variances caused by nonrelevant factors to measure change only caused by differences in the variable of interest (Green et al. 1994). In consequence of, vegetation pigment absorption, the reflected red energy decreases, and the reflected NIR energy increases as a result of the strong scattering processes of healthy leaves within the canopy. The reflection of red and NIR radiation spectrum to the biophysical characteristics of vegetation become interaction energy at the canopy level, background, and atmospheric impacts and give the unique signal to the satellite sensors that can show leave and tree condition.

The NDVIs properties help mitigate a large part of the variations that result from the overall remote-sensing system (radiometric, spectral, calibration, noise, viewing geometry, and changing atmospheric conditions). Some land-surface types are not robustly represented by NDVI, such as snow, ice, and non-vegetation surfaces, where atmospheric variations and sensor characteristics dominate. It has been used to detect the vegetation dynamics and land cover changes at the regional and global scales (Barichivich et. al: 2013).

Some studies and findings from scientist who observed and researched the impact of ash volcanic eruption and vegetation indices change. Ann De Schutter et.al (2015) noticed that 2007 eruption of Oldoinyo Lengai, North Tanzania, was severely affecting the vegetation by volcanic ash fall and they noted that the estimated recovery time varies from more than 5 years to less than 6 months with increasing distance from the volcano. Jennifer Rozier (2015) observed the patterns of vegetation change over time on eruption of El Chichón volcano. Her result is: indication of vegetation coverage that was reached within 20 years of the eruption, is showing rapid recovery.

\section{METHOD}

In this study, ArcGIS software was applied as a tool to analyze data. Measuring and calculating both of temperature and NDVI used band 4, band 5 near infrared, band 10 thermal infrared 1 and band 11 thermal infrared 2 from Landsat 8's brightness temperature at satellite.

In this study, working procedures were:

A. Convert the raw bands into Top of Atmosphere Radiance $\left(\right.$ TOA $\left._{r}\right)$

OLI and TIRS band data can be converted to TOA spectral radiance using the radiance rescaling factors provided in the metadata file: where:

$$
L_{\lambda}=M_{L} Q_{c a l}+A_{L} \ldots \ldots \ldots \ldots \ldots \ldots(1)
$$

$L_{\lambda} \quad=$ TOA spectral radiance (Watts/ $\left.(\mathrm{m} 2 * \operatorname{srad} * \mu \mathrm{m})\right)$

$M_{L} \quad=$ Band-specific multiplicative rescaling factor from the metadata (RADIANCE_MULT_BAND_x, where $\mathrm{x}$ is the band number)

$A_{L} \quad=$ Band-specific additive rescaling factor from the metadata (RADIANCE_ADD_BAND_x, where $\mathrm{x}$ is the band number)

$Q_{c a l}=$ Quantized and calibrated standard product pixel values $(\mathrm{DN})$

\section{B. Conversion to TOA Reflectance}

OLI band data can also be converted to TOA planetary reflectance using reflectance rescaling coefficients provided in the product metadata file (MTL file). The following equation is used to convert DN values to TOA reflectance for OLI data as follows:

where:

$$
\rho \lambda^{\prime}=M_{\rho} Q_{c a l}+A_{\rho} \ldots \ldots \ldots \ldots
$$

$\rho \lambda^{\prime}=$ TOA planetary reflectance, without correction for solar angle. Note that $\rho \lambda^{\prime}$ does not contain a correction for the sun angle.

$M_{\rho} \quad=$ Band-specific multiplicative rescaling factor from the metadata (REFLECTANCE_MULT_BAND_x, where $\mathrm{x}$ is the band number)

$A_{\rho} \quad=$ Band-specific additive rescaling factor from the metadata (REFLECTANCE_ADD_BAND_x, where $x$ is the band number)

$Q_{\text {cal }}=$ Quantized and calibrated standard product pixel values (DN)

TOA reflectance with a correction for the sun angle is then:

$$
\rho \lambda=\frac{\rho \lambda^{\prime}}{\cos \left(\theta_{S Z}\right)}=\frac{\rho \lambda^{\prime}}{\sin \left(\theta_{S E}\right)}
$$

where:

$\rho \lambda=$ TOA planetary reflectance

$\theta_{S E} \quad=$ Local sun elevation angle. The scene center sun elevation angle in degrees is provided in the metadata (SUN_ELEVATION).

$\theta_{S Z} \quad=$ Local solar zenith angle; $\theta_{S Z}=90^{\circ}-\theta_{S E}$

For more accurate reflectance calculations, per pixel solar angles could be used instead of the scene center solar angle, but per pixel solar zenith angles are not currently provided with the Landsat 8 products.

\section{Conversion to At-Satellite Brightness Temperature}


TIRS band data can be converted from spectral radiance to brightness temperature using the thermal constants provided in the metadata file:

$$
T=\frac{K 2}{\ln \left(\frac{K 1}{L \Omega}+1\right)}
$$

where:

$T=$ At-satellite brightness temperature $(\mathrm{K})$

$L_{\lambda} \quad=$ TOA spectral radiance $($ Watts $/(\mathrm{m} 2 * \operatorname{srad} * \mu \mathrm{m}))$

$K_{1} \quad=$ Band-specific thermal conversion constant from the metadata (K1_CONSTANT_BAND_x, where $\mathrm{x}$ is the band number, 10 or 11 )

$K_{2} \quad=$ Band-specific thermal conversion constant from the metadata (K2_CONSTANT_BAND_x, where $\mathrm{x}$ is the band number, 10 or 11)

\section{Observe temperature distribution and NDVI between before and after eruption}

Common formula that were used to identify vegetation indices from satellite images by their visible and infrared bands to show quantify the density of plant growth on the Earth surface by calculating near-infrared radiation minus visible radiation divided by near-infrared radiation plus visible radiation. The result of this calculation describes NDVI on areas.

$$
N D V I=\frac{(N I R-R E D)}{(N I R+R E D)}
$$

Calculations of NDVI for a given pixel always result in a number that ranges from minus one $(-1)$ to plus one $(+1)$; however, no green leaves give a value close to zero. A zero means no vegetation and close to $+1(0.8-0.9)$ indicates the highest possible density of green leaves.

\section{FINDING AND DISCUSSION}

Mount Kelud eruption happened in 2014 and it produced a huge volcanic dust cloud that was mainly blown almost covered Java and Bali island with volcanic ash fall. Dust cloud and ash fall from this strato-volcano forced the closing of several airports and made people to keep staying in their house caused by its disturbance. This eruption affected to local weather. This eruption relatively had no or small climatic effects. It was because the volcanic ash and volcanic dust in atmosphere relatively brought down to the ground by heavy rain fall after eruption. Dust injection that was produced by its eruption did not impact to long-lived volcanic hazes in the stratosphere, and it did not relatively widespread around the planet to try cooling planet by injecting large amounts of particles into the stratosphere to reflect some of the solar radiation. In this article, temperature change pre and post volcanic eruption observed by temporal comparison of satellite images.

Sets of USGS Landsat 8 images were observed in the same rainy seasons around Mt. Kelud between November 2013 to March 2014. Based on satellite data analyzing, pixels percentage of raster data that described the temperature of images had various pattern values per month. Before eruption,
November 2013 satellite data, coverage area were dominated by pixel value $<15^{\circ} \mathrm{C}$ (around $36.4 \%$ ), but still have the hotter area calculated in $>40^{\circ} \mathrm{C}$ around $21.2 \%$ (see Fig. 2a). During eruption, data satellites from Landsat 8 really not good, because of covered by dust cloud that make sensor disturbance catching data. 10-days satellite data (21 February 2014) after eruption were applied for observation with decent and reliable data to be analyzed. On that moment, temperature condition increased rapidly compared the previous satellite data. The temperature condition reached the higher than normal condition. Pixel values upper $40^{\circ} \mathrm{C}$ had dominant coverage (around $57.8 \%$ ) that high different from the lower value $3.2 \%$ on $<15^{\circ} \mathrm{C}$ pixels (see Fig. 2b). Otherwise, the temperature after eruption showed trend back to normal condition. Satellite image analyzing from a month after eruption described that the temperature condition relative slightly declined down to the normal. But, the interesting thing is there was the temperature pattern on the west and north sides. The pattern showed that there was accumulation pattern of temperature condition on west and north because of the wind orientation blew from east to the west-north. This type of character made like surrounding Mt. Kelud divided to two temperature pattern that east and south sides were cooler than west and north sides. Data after eruption (March 2014) showed that the red and near red reach $>40^{\circ} \mathrm{C}$ around $31.3 \%$ on West on North smaller than greenblue described lower temperature $<15^{\circ} \mathrm{C}$ around $39.2 \%$ on East and South (see Fig. 2c).

NDVI values were observed by the same set of satellite images that were derived from temperature analyzed images. Vary of values between November 2013 to March 2014 showed the land cover condition, especially describe of leaves and trees spectrum reflection. Generally, before and after eruption, the NDVI illustrated the relative constant condition, just like the values dominated by 0 to 1 index. This value indicated that observed areas relative have good land cover, trees and leaves condition. The differences value of NDVI between pre and post disaster clearly stated on after 10-days satellite images data. Pre-volcanic eruption, NDVI on November 2013 showed curve tended 0 to 0.7 value distribution that peak located on 0.4 values (see Fig. 2g). During eruption (21 February 2014) data, the values between 0 to 0.25 increased in proportion, but the curve peak relatively same on 0.4 value. It showed us that during eruption some green leaves and trees became dried, values near 0 increased and reached sub-peak disturbance on normal curve. This case happened in reason of much leaves and trees lost green pigment and a few dried that make the reflectance caught by sensor satellite and derived from separating sub-indices curve on near 0.25 (see Fig. 2h). Therefore, a month after eruption (24 March 2014) the NDVI's values, even though peak curve still relative reached on 0.4 index, NDVI reformed to slightly normal curve condition (see Fig. 2i). 
1 November 2013

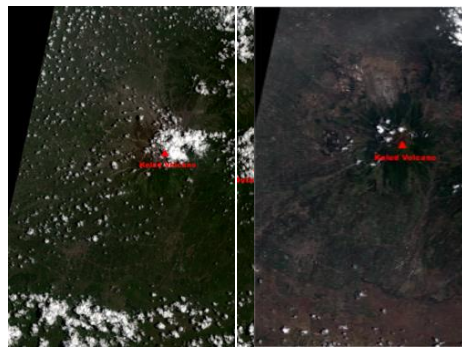

24 March 2014

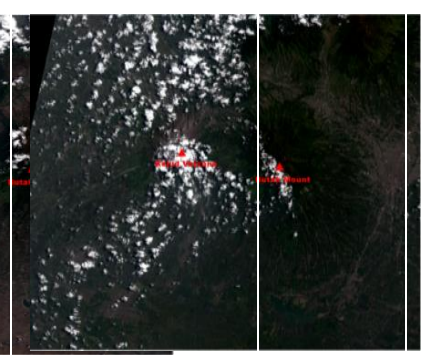

TEMPERATURE CHANGE

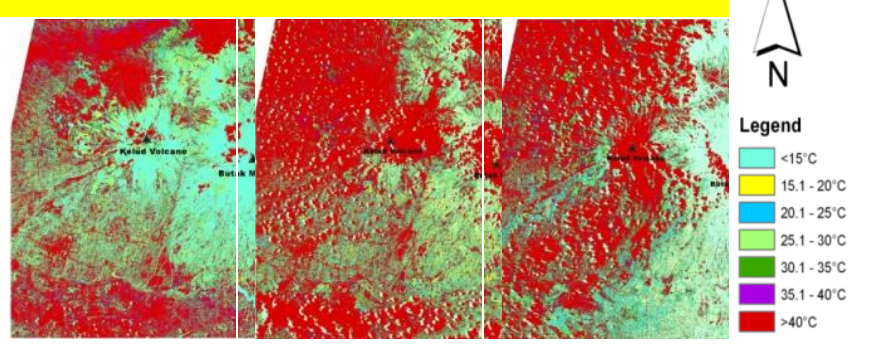

(a)

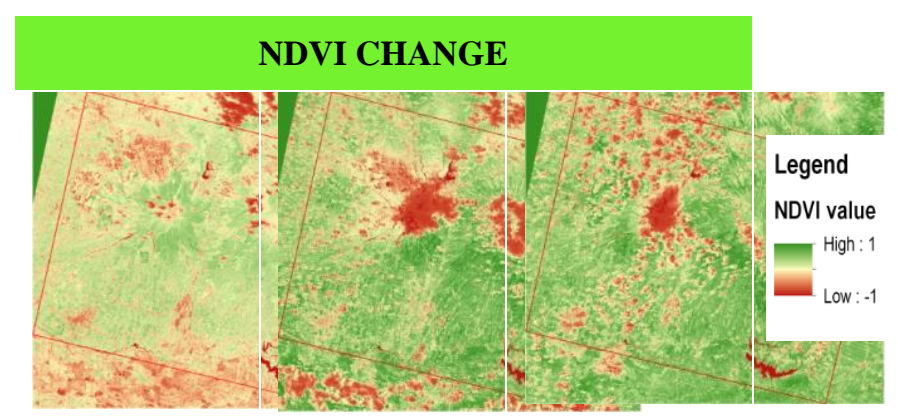

(d)

(e)

(f)

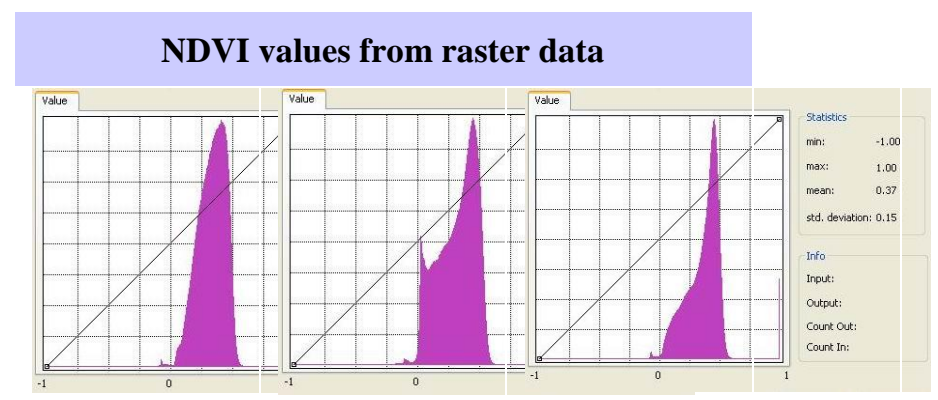

(g)

(h)

Fig 2. Satellite data Pre, During and Post Volcanic Eruption on Around of Mt Kelud, East Java, Indonesia; Temperature change condition described on (a), (b), (c); NDVI change condition illustrated on (d), (e), (f); and the Graphs of NDVI values showed on $(\mathrm{g}),(\mathrm{h}),(\mathrm{i})$.

\section{CONCLUSION AND SUGGESTION}

Landsat- 8 that has TIRS bands can drive and show the good data of thermal surface description. Temperature change that is derived from Landsat- 8 illustrated the temperature and effect of volcanic ash fall, comparing NDVI that showed exsiccate vegetation and growing leaves speed at post volcanic eruption. The Earth temperature increased dramatically up to $40^{\circ} \mathrm{C}$ during eruption while NDVI's values dropped down to nearly 0,25 index. The volcanic ash-fall effected directly to both temperature and NDVI components. It showed that during eruption some green leaves and trees lost their green pigment that were resulted to different reflectance value caught by Landsat-8 sensors. Spatial analysis of temperature and vegetation indices with Landsat- 8 images can be derived easily with a great data validity in both short and long observation. In concern of specific agricultural or agroforestry evaluation and monitoring, using more precise with more high scale of satellite images are strongly suggested to get more valid measured results. Vegetation indices interpretation on volcanic hazard eruption has wide range limitation relatively because of smoke, ash-fall and volcanic cloud. Furthermore, to use more set temporal data varies are highly recommended to get more detail values from leaves condition and reflection.

\section{REFERENCES}

[1] Robert Wright, Andrew J.L., Harris, Ronnie Torres, Luke P. Flynn, 2015," The effects of volcanic eruptions observed in satellite images: Examples from outside the North Pacific region," Springer Berlin Heidelberg.

[2] Ramsey M.S., Harris A.J.L., "Volcanology 2020: How will thermal remote sensing of volcanic surface activity evolve over the next decade?," J. Volcano, Geothermal Res. 2012.

[3] Matthew Blackett, 2014, "Early Analysis of Landsat-8 Thermal Infrared Sensor Imagery of Volcanic Activity," Journal: Remote Sensing.

[4] USGS, Frequently Asked Questions about the Landsat Missions; 2013, http://landsat.usgs.gov/band_designation_landsat_satellites.php.

[5] Reuter, D., Richardson, C., Irons J., Allen R., Anderson M., Budinoff J., Casto G., Coltharp C., Finneran P., Forsbacka B., et al, "The Thermal Infrared Sensor on the Landsat Data Continuity Mission," In Proceedings of 2010 IEEE International Geoscience and Remote Sensing Symposium (IGARSS), Honolulu, HI, USA, 25-30 July 2010, pp. 754-757.

[6] Pieri D., Abrams M., ASTER watches the world's volcanoes: A new paradigm for volcanological observations from orbit," J. Volcanol, Geothermal Res. 2004.

[7] Tim Hess, William Stephens and Graham Thomas, 1996, "Modelling NDVI from decadal rainfall data in the North East Arid Zone of Nigeria," Journal: Journal of Environmental Management.

[8] Molly E. Brown, Jorge E. Pinzón, Kamel Didan, Jeffrey T. Morisette, and Compton J. Tucker, 2006, "Evaluation of the Consistency of LongTerm NDVI Time Series Derived From AVHRR, SPOT-Vegetation, SeaWiFS, MODIS, and Landsat ETM+ Sensors,” Journal: Geoscience and Remote Sensing.

[9] Green K., Kempka D., Lackey L., (1994), "Using remote-sensing to detect and monitor land-cover and land-use change," Photogramm Eng Remote Sens 60(3):331-337.

[10] Barichivich J., Briffa K. R., Myneni R. B., et al, 2013, "Large-scale variations in the vegetation growing season and annual cycle of atmospheric CO2 at high northern latitudes from 1950 to 2011," Global Change Biology.

[11] Ann De Schutter, Matthieu Kervyn, Frank Canters, Sonja A BosshardStadlin, Majura A M Songo, Hannes B Mattsson, 2015, “Ash fall impact 
on vegetation: a remote sensing approach of the Oldoinyo Lengai 200708 Eruption," Journal: Applied of Volcanology.

[12] Jennifer Rozier, 2015, "Thesis: Vegetation Response and Recovery in the 20 years following the 1982 eruption of El Chichón volcano: A Remote Sensing Approach," Kingston University, London.

[13] Anonym, 2013, Using the USGS Landsat 8 Product, United States of Geological Survey (USGS), https://landsat.usgs.gov/using-usgs-landsat8-product, Accessed 7 July 2014.

[14] Anonym, 2011, Landsat 7 Science Data Users Handbook, National Aeronautics and Space Administration (NASA) http://landsat.gsfc.nasa.gov/landsat-7-science-data-users-handbook/.

Accessed 4 October 2014. 